\title{
Parallel Control to Fragments of a Cylindrical Structure Driven by Explosive inside
}

\author{
Wenkai Chen, Xiangyu Li, Fangyun Lu, Zhenduo Li, and Zhenyu Zhang \\ College of Science, National University of Defense Technology, Changsha, Hunan 410073, China \\ Correspondence should be addressed to Xiangyu Li; xiangyu_lee@163.com
}

Received 30 August 2014; Accepted 8 December 2014

Academic Editor: Yi-Chung Hu

Copyright ( 2015 Wenkai Chen et al. This is an open access article distributed under the Creative Commons Attribution License, which permits unrestricted use, distribution, and reproduction in any medium, provided the original work is properly cited.

\begin{abstract}
By analyzing the fragmentation distributions of a cylindrical structure and a specific structure, the necessity of parallel control to the fragments is presented. The shell shape of structures has an influence on the fragment spatial distribution. A new design method for the shell shape is proposed. To facilitate the establishment of the numerical model and the machining for relative experiments, the mathematical description of the theoretical calculated generatrix of the shell is simplified. The fragment spraying processes of the designed structures are simulated, and end effects are analyzed. Based on the theoretical design and plentiful simulation data, the relationships between the size of the parallel fragmentation structure and the optimized curvature radius of the shell are expressed by an equation. The equation is validated by numerical means and can be a reliable reference to the design of the parallel fragmentation structure.
\end{abstract}

\section{Introduction}

Cylindrical structure with explosive inside is widely used in the mining, blasting engineering, and military weapon. In modern warfare, the vulnerability of the target is greatly reduced with the development of technology. Due to the enhanced protection of every component, the target is often still able to work, when it suffers a large area of low-density damage. However, the dependence of the target on every component rises. Sometimes only a component failure can lead to the complete strike of the target $[1,2]$. Consequently, the most efficient path to destroy the target is the high-density regional damage $[3,4]$.

For the conventional cylindrical structure, because of the end effects caused by the rarefaction wave at the ends of the structure, the ejection angle of fragments increases. That is to say, the width of the fragments spatial distribution along the axial direction becomes wider, which lowers the density of fragment distribution. Thus, the fragments could not achieve a high-density damage to the target and become ineffective for the most parts. The further the fragments spray, the lower the utilization ratio of the fragments is.

Modern requirements for increased warhead lethality with decreased mass, together with their use in complex systems, mean that many systems are amiable $[5,6]$. Focusing fragmentation warhead through the specific structure decreases the ejection angle of fragments. The fragments are gathered together in a much narrower spatial width, which makes a cutting damage to the target come true. However, owing to the immutability of the specific structure, the high ability of focusing fragments can only be achieved in a constant distance, and fragments are likely to collide with each other in the focusing region [7-9]. In the actual encountering situation between the missile and the target, the missile and the target usually occur at a high speed impact, which would lead to large differences between the actual encountering distance and the desired distance. The large difference in the encountering distance leads to the reduction of damage effect to the target. The fragments of structures are always densely arranged in the assembly process, which makes the fragment density maximize along the axial direction optimally. So the best way to achieve the ability to focus fragments along the axial direction is by making all the fragments spray horizontally, perpendicular to the axial direction.

The parallel fragmentation structure presented in this paper is based on the design of the focusing fragmentation warhead and can achieve high-density effective damage to 


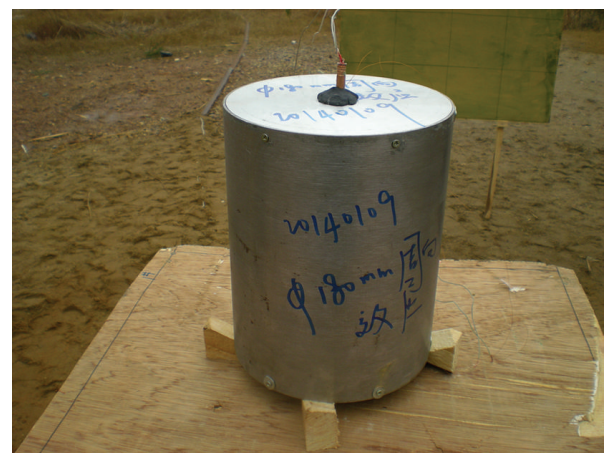

Figure 1: Facade of structure.

the target. The key technology of the structure is the design of the shell shape. This paper demonstrates a new method to design the shell shape of the structure and a new definition of deflecting angle, which is a new parameter to describe the performance of fragments. The equation that describes the relationship between the size of the parallel fragmentation structure and the curvature radius of the arc equalizing the generatrix of shell is attained and optimized with the relevant numerical simulation results. The equation can be a quick and easy design method for the parallel fragmentation structure.

\section{Experiment}

In the experiments related to conventional cylindrical structures, it is easy to find that the fragments distribute dispersedly and the width of the fragments' spatial distribution along the axial direction is much bigger than the height of the structure.

2.1. Experiment Preparation. The cylindrical structure is centrally symmetrical and the shape is cylindrical, as shown in Figure 1. The outer diameter of the structure is $180 \mathrm{~mm}$ and the height is $200 \mathrm{~mm}$. The cylindrical structure in the experiment comes in several parts, as seen in Figure 2. The covers are made of $10 \mathrm{~mm}$ thick LY-12 aluminum, and the shells are made of $2 \mathrm{~mm}$ thick 1020 steel. The fragments are alloy steel spheres, and the diameter of the spheres is $8 \mathrm{~mm}$. All the fragments are arranged closely to each other and fixed with epoxy resin between the inner shell and the outer shell. The explosive is JHL-3, which is a type of high energy explosive, and is detonated by an $8 \mathrm{~mm}$ diameter exploder from the top of structure [10-12].

The target is $3 \mathrm{~mm}$ thick, $1.5 \mathrm{~m}$ long, and $1.26 \mathrm{~m}$ wide steel plane. To simplify the collection and analysis of experimental data, we mesh the target into 20 lattices, as depicted in Figure 3.

Figure 4 shows the arrangement of target and the structure. The distance between the structure and target is $3.5 \mathrm{~m}$. The structure is arranged vertically on a wooden frame, and the axis of the structure is parrallel to the ground. After the explosive is detonated, the shock wave appears and reflects from the ground to the original position. In order to avoid the effects of the shock wave on the process that fragments

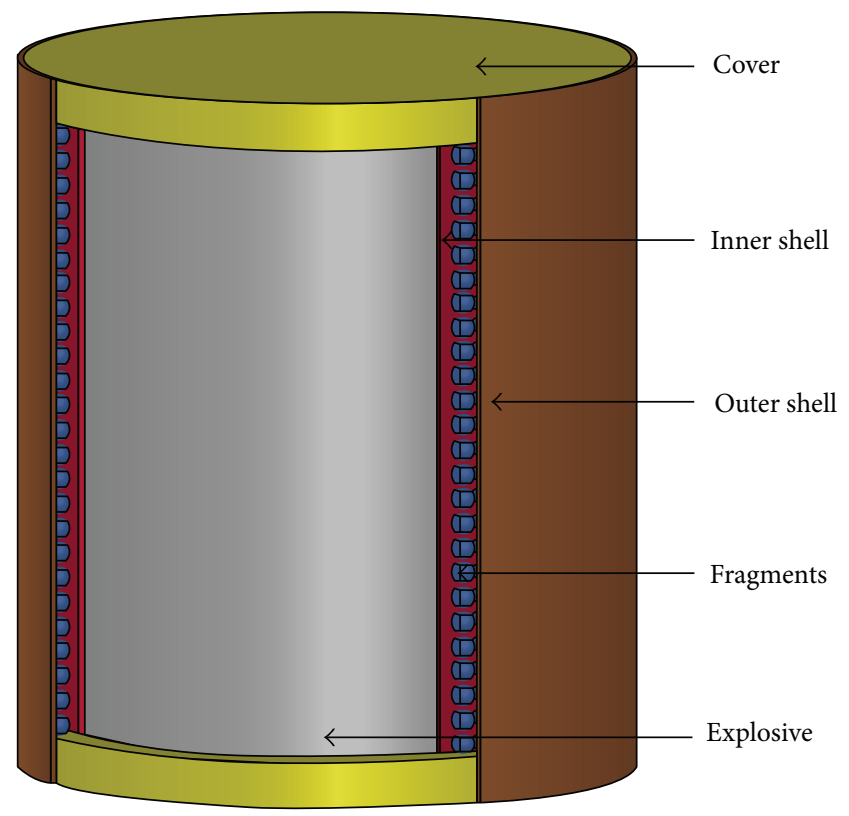

FIGURE 2: Components of cylindrical structure.

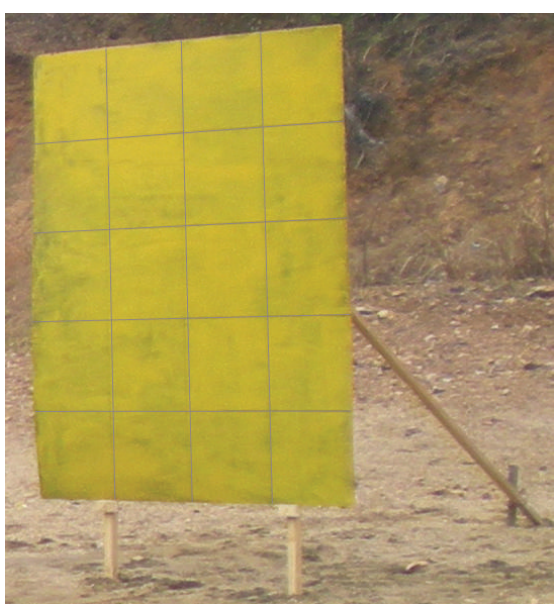

FIGURE 3: Target plane.

spray away from shell, the distance between the structure and the ground should be not less than $1.5 \mathrm{~m}$ [14]. On the circle whose center is the structure and radius is $3.5 \mathrm{~m}$, two targets are arranged. Each target can blanket $20.74^{\circ}$ of the circle, so $11.52 \%$ of the fragments can be intercepted by the two targets. The two targets and the structure are in a line. Besides, the equatorial plane of the structure crosses the line which is $0.8 \mathrm{~m}$ far away from the upper edge of the target.

2.2. Damage to the Targets. Because the structure is centrally symmetrical, the distribution of fragments on the two targets can reflect the characteristics of all the fragments adequately. Figure 5 shows the damage to the targets made by the structure, and we can observe that there are plenty of holes on the targets. A lot of big holes are made by bursting the shells in high velocity, whilst the majority of the regular holes 


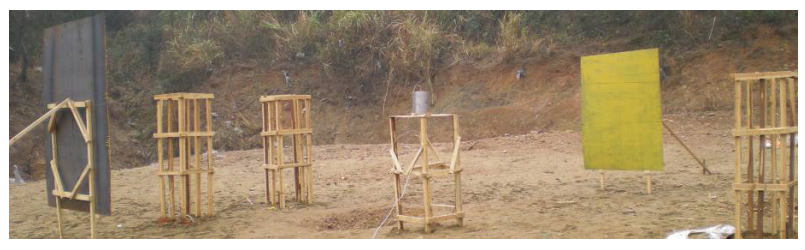

FIGURE 4: Arrangement of target and the structure.

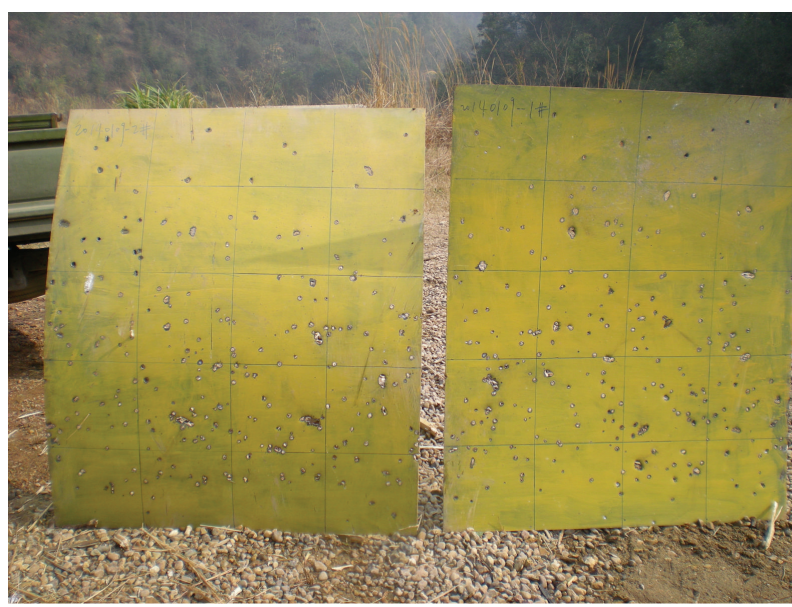

FIGURE 5: Damage to the targets by the structure.

are made by the fragments. Based on the distribution of the holes on the targets, we calculate a number of statistics about the number of fragments crossing the targets, as depicted in Figure 6.

2.3. Discussion. Firstly, we can see that the region of fragments nearly covers all the targets. The width of fragment distribution along the axial direction is wide. With the increase of spraying distance, the width would become wider and many more fragments would become invalid.

Secondly, it is obvious that the whole distribution of fragments is slightly to the downside of the equatorial plane of the structure. The main influences are that the explosive is detonated from the top of the structure and the shock wave propagates from up to down. The direction where the shock wave propagates makes a significant impact on the direction where the fragments spray.

Thirdly, it seems that part of the fragments concentrate in the range from $30 \mathrm{~cm}$ to $60 \mathrm{~cm}$ on the targets. In fact the spraying directions of fragments near the ends deviate from the equatorial plane of the structure too much, which is caused by the end effects.

Optimizing the distribution of fragments, the structure is redesigned. This paper presents a new cylindrical structure, named as the parallel fragmentation structure.

\section{Analysis and Structure Design}

The significant characteristics of the parallel fragmentation structure are that the fragments spray in parallel. In this

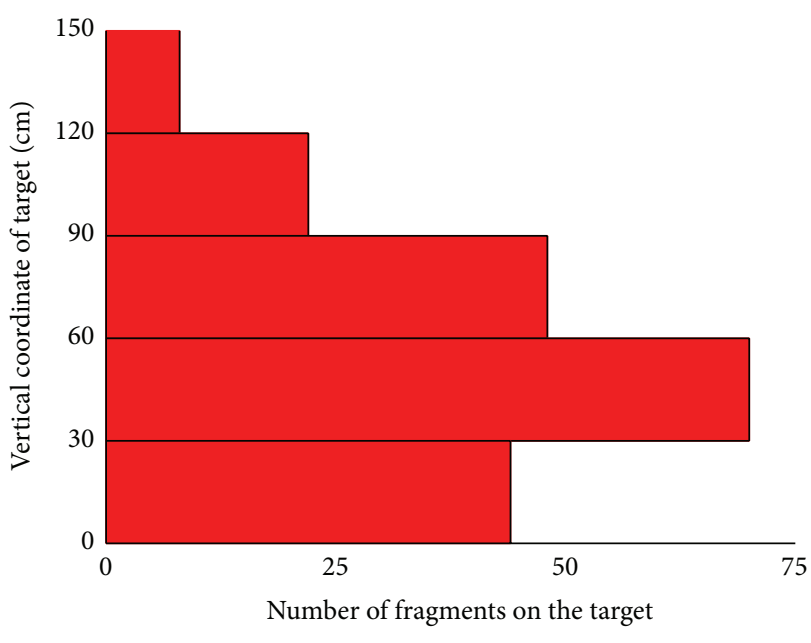

FIGURE 6: Statistics about the number of fragments crossing the targets.

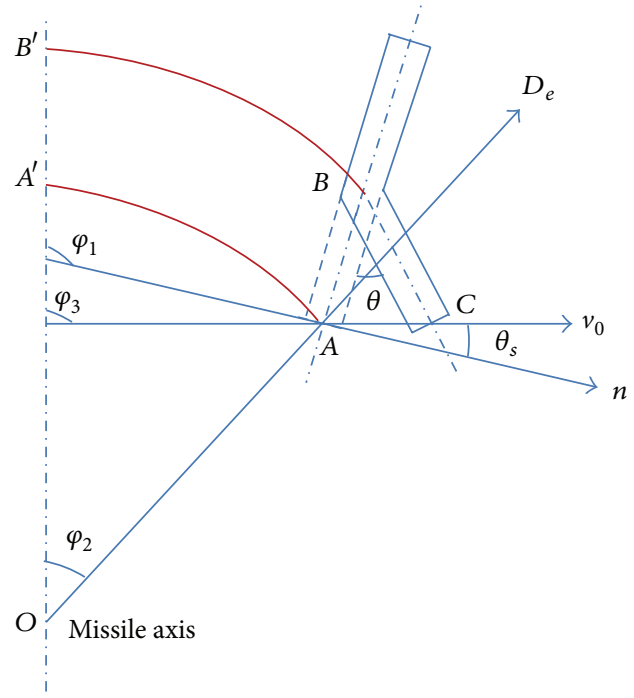

FIgURE 7: Calculation of ejection angle of fragments.

section, the details on the spraying process of fragments are discussed, followed by a method to design the shape of the shell which is proposed, and, lastly, the case of end effects is considered.

3.1. Process of Fragments Spraying. According to the Shapiro theory, the detonation wave propagates in the form of a spherical wavefront, outward from the booster explosive or the booster detonator.

Now let us take an infinitesimal element $A B$ of the shell as the study point $[15,16]$. In Figure $7, \varphi_{1}, \varphi_{2}$, and $\varphi_{3}$ are the angles between the missile axis and the normal line of the shell, the normal line of detonation wavefront, and the velocity vector of the infinitesimal element $A B$, respectively. $\theta_{s}$ is the angle between the normal line of the shell and the velocity vector of the infinitesimal element $A B . \theta$ is the angle that the infinitesimal element $A B$ turns. $O$ is the detonation point. 
Here, we put forward a series of hypotheses about the detonation wave. The detonation wave propagates to the ends from the center of the structure. The direction of the detonation wave keeps unaltered, after the detonation wave impacts the shell of the structure.

The law of fragments spraying away from the shell is fitted to Shapiro law, expressed as

$$
\tan \theta_{s}=\frac{v_{0}}{2 D_{e}} \cos \left(\frac{\pi}{2}-\varphi_{1}+\varphi_{2}\right),
$$

where $v_{0}$ is the velocity of fragment spraying from the shell and $D_{e}$ is the explosive velocity. We can see that the ejection angle of fragments is related to the detonation point and the direction where the detonation wave propagates.

The Shapiro law indicates that the time for the infinitesimal element $A B$ to accelerate to its final speed from rest is instantaneous. During the derivation of Shapiro law [17], the distance between point $A$ and point $C$ is expressed as

$$
\overline{A C}=v_{0} \Delta t .
$$

$\Delta t$ is the period of time for the element $A B$ transforming to $C B$. However, the acceleration of the infinitesimal element $A B$ cannot be neglected. Because the infinitesimal element keeps accelerating throughout the expanding process, we can regard $v_{0} / 2$ as the average velocity during the process where the point $A$ of element $A B$ transforms to point $C$. The relationship (2) is redefined as

$$
\overline{A C}=\frac{1}{2} v_{0} \Delta t .
$$

Based on the above analysis, the Shapiro law (1) is revised as

$$
\tan \theta_{s}=\frac{v_{0}}{4 D_{e}} \cos \left(\frac{\pi}{2}-\varphi_{1}+\varphi_{2}\right) .
$$

From Figure 7, we know the relationship among $\varphi_{1}, \varphi_{3}$, and $\theta_{s}$ to be

$$
\varphi_{1}=\theta_{s}+\varphi_{3} .
$$

The most attractive characteristic of the new structure, proposed in this paper, is that the fragments spray in parallel; that is, the angle $\varphi_{3}$ is 90 degrees. The relationship (5) can be written as

$$
\varphi_{1}=\theta_{s}+\frac{\pi}{2} .
$$

Using the above relationship (6) between $\varphi_{1}$ and $\theta_{s}$, the revised Shapiro law (4) can be simplified as

$$
\tan \theta_{s}=\frac{v_{0}}{4 D_{e}} \cos \left(\theta_{s}+\varphi_{2}\right) .
$$

The parameter $\varphi_{2}$ can be calculated through the initial located position of the infinitesimal element and the initiation point. The explosive velocity $D_{e}$ is determined by the type of explosive. With the solution of $v_{0}$ in the next section, the angle $\theta_{s}$ also can be solved.
TAble 1: Parameters of explosives [13].

\begin{tabular}{lccc}
\hline Explosive category & $D_{e}\left(\mathrm{~m} \cdot \mathrm{s}^{-1}\right)$ & $\rho_{e}\left(\mathrm{~g} \cdot \mathrm{cm}^{-3}\right)$ & $\sqrt{2 E}\left(\mathrm{~m} \cdot \mathrm{s}^{-1}\right)$ \\
\hline TNT & 6640 & 1.59 & 2316 \\
Comp.B & 7840 & 1.68 & 2682 \\
RDX & 8180 & 1.65 & 2834 \\
HMX & 8600 & 1.84 & 2895 \\
PETN & 7980 & 1.73 & 2834 \\
Tetry & 7850 & 1.62 & 2500 \\
Octol & 8643 & 1.80 & 2895 \\
\hline
\end{tabular}

3.2. Initial Fragment Velocity and Gurney Specific Energy. The initial fragment velocity $v_{0}$ is expressed in the Gurney formula [18-20], which is given by

$$
v_{0}=\sqrt{2 E} \sqrt{\frac{\beta}{1+0.5 \beta}},
$$

where $\beta$ is the ratio of charge mass to the shell mass of the unit height cylinder and $\sqrt{2 E}$ is the Gurney constant or Gurney specific energy. Every explosive has a specific Gurney constant, which represents the component and feature of explosive, as shown in Table 1 . The Gurney constant is related to the loading density of the explosive and other factors. By experimentation, a linear correlation is found between the Gurney constant and the explosive velocity and is given by

$$
\sqrt{2 E}=0.52+0.25 D_{e}
$$

where the explosive velocity $\left(D_{e}\right)$ and the Gurney constant $(\sqrt{2 E})$ have the same dimension.

3.3. Structure Design. The finite method is used for the design of structure in any size. The design of the parallel fragmentation structure is shown in Figure 8. The origin of the coordinate system is located at the geometrical center of the structure, and the $y$-axis with respect to the coordinate is defined by the space-axial position. In Figure 8 , the dotted line is a quarter boundary of the half-section of the shell, and the length of the infinitesimal element $\left(M_{1} M_{2}\right)$ is $l$.

According to the height $(H)$ and the diameter $(L)$ of the structure, we can get the coordinate of point $M_{1}(H / 2, L / 2)$. Then, by means of a trigonometric calculation, the value of angle $\varphi_{2}$ is obtained. Inserting the value of angle $\varphi_{2}$ to (5), the numerical solution of the angle $\left(\theta_{s}\right)$ between the normal line of the shell and the velocity vector of the infinitesimal element $\left(M_{1} M_{2}\right)$ can be solved, with the results that the coordinate of $M_{2}$ can be given by $\left(X_{M_{1}}-l * \sin \theta_{s}, Y_{M_{1}}-l * \cos \theta_{s}\right)$. By analogy, we can get every terminal coordinate of the infinitesimal elements, such as $M_{3}, M_{4}, \ldots, M_{n}$, depicted in Figure 8 . Liner fitting to all terminals can lead to an equation of the generatrix of the shell. In order to facilitate the establishment of the numerical model and the machining for relative experiments, we equate the generatrix of the shell to an approximate arc, whose curvature radius can be calculated by the relevant geometric relationships as shown in Figure 9.

For a designed fragmentation structure whose height and diameter are both $200 \mathrm{~mm}$, the comparison of the theoretical 

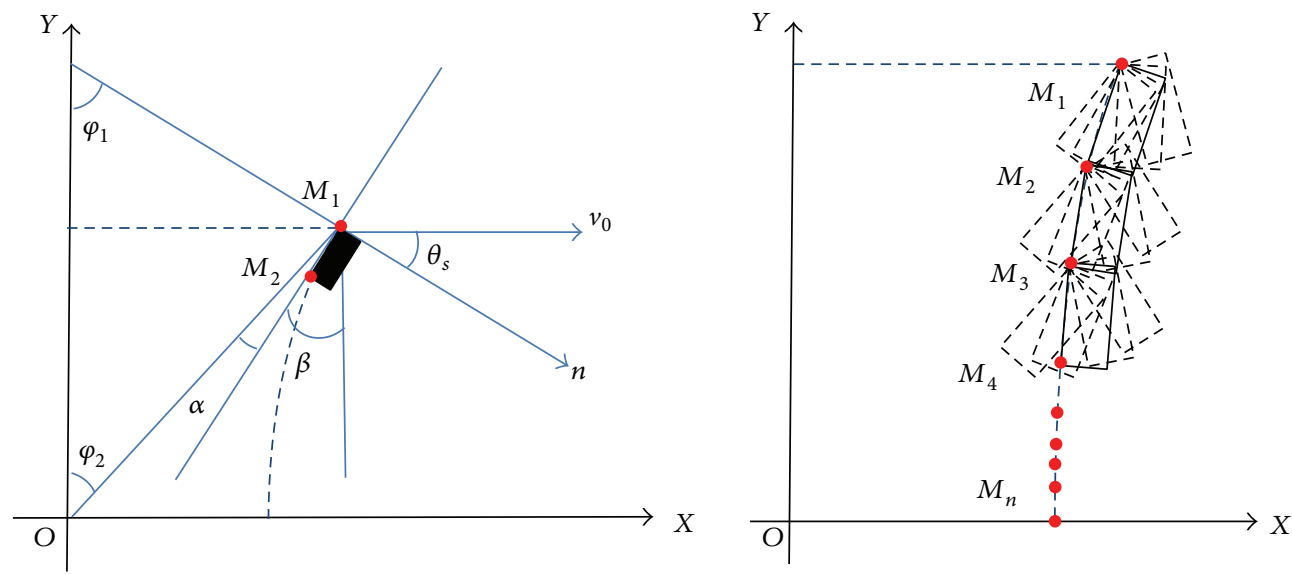

Figure 8: Design approach.

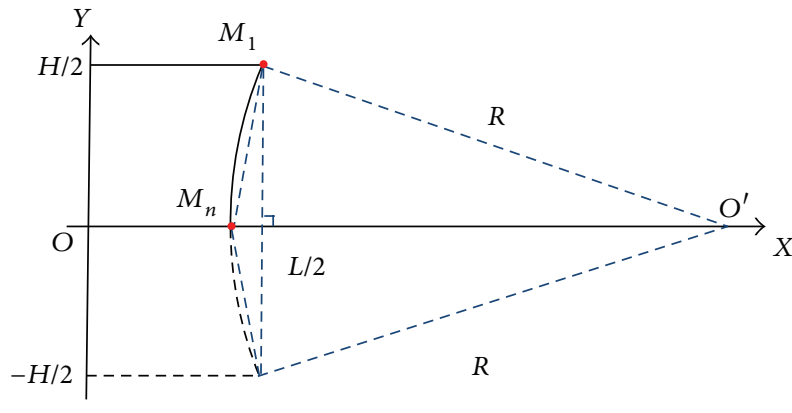

FIGURE 9: Geometric relationships to calculate curvature radius.

calculated generatrix of its shell and the equivalent arc is shown in Figure 10. It should also be noted that the coordinate system in Figure 10 is similar to the one in Figure 8. It is obvious that, in general, the equivalent arc is similar to the theoretical calculated generatrix and simplifies the mathematical description of the generatrix effectively.

3.4. End Effects. One of the problems in the design of structures is the end effects influencing the ejection angle of fragments near the ends. It is well known that significant differences exist between the ejection angle of fragments located in the center of the structure and those of fragments located near the ends of the structure. For the purpose of minimizing the end effects, a new component of platform is proposed [21]. Next, we will talk about the new definition of the deflecting angle proposed in this paper.

The performance of fragmentation structures is usually described with characteristics of the fragment dispersion and includes mass, ejection angle, direction angle, velocity, and the distribution density of fragments [22-25]. The ejection angle $(\varphi)$ and direction angle $(\Omega)$, shown in Figure 11, are studied widely in designing fragmentation structures. The direction angle is the angle between the midline with $45 \%$ effective fragments on each side and the equatorial plane through the barycenter. All the explosives are detonated from the geometrical center of the structures, and the parallel fragmentation structure is symmetrical, so the direction angle fluctuates around $0^{\circ}$ and is not discussed further in this paper. The ejection angle is the cone angle which includes $90 \%$ effective fragments.

However, the ejection angle cannot describe the relationship between the fragment dispersion and the structure but can only show the characteristics of the fragment dispersion. The deflecting angle $(\theta)$ is proposed in this paper, which is the average between the upper deflecting angle $\left(\theta_{1}\right)$ and the lower deflecting angle $\left(\theta_{2}\right)$. The upper deflecting angle $\left(\theta_{1}\right)$ is the angle between the upper boundary of the ejection angle and the plane through the upper surface of the structure, so as to the lower deflecting angle $\left(\theta_{2}\right)$.

The fragment spraying process of the cylindrical structure, whose height and diameter are both $200 \mathrm{~mm}$, and the modified structure with $30 \mathrm{~mm}$ high platform on each end is simulated. The fragment distributions on the target plane (distance 3.5 meters) are shown in Figure 12. It is obvious that the platform can minimize the end effects effectively. The deflecting angle of the cylindrical structure is $8.42^{\circ}$. The angle of the modified cylindrical structure is $3.96^{\circ}$, reducing the reflecting angle by $4.46^{\circ}$. The modified structure is $60 \mathrm{~mm}$ longer than the cylindrical structure. Considering whether the change of structure height makes the decrease of deflecting angle, another cylindrical structure is modeled, which is of $260 \mathrm{~mm}$ height and $200 \mathrm{~mm}$ diameter. The deflecting angle of the longer cylindrical structure is $8.85^{\circ}$, which is similar to the one of $200 \mathrm{~mm}$ height cylindrical structure, so the height of the structure does not play an important role in influencing the deflecting angle and the platform can minimize the end effects effectively.

\section{Numerical Simulation and Discussions}

The numerical model is made using the nonlinear, explicit finite element code LS-DYNA (version 970). The method to design the shell shape is tested by numerical simulation. Considering the influences on the deflecting angle, the parallel fragmentation structure is optimized. 

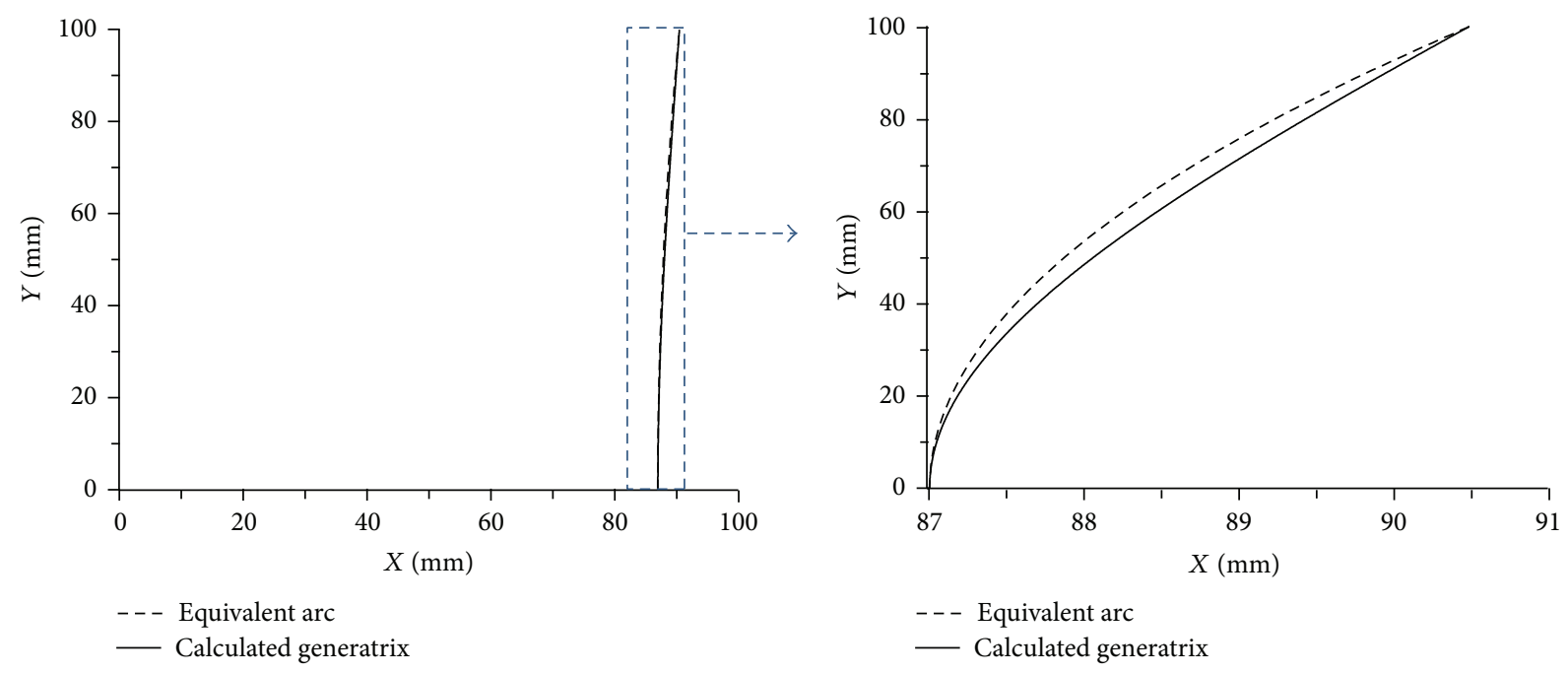

FIGURE 10: Comparison of the theoretical calculated generatrix of the inner shell and the equivalent arc.

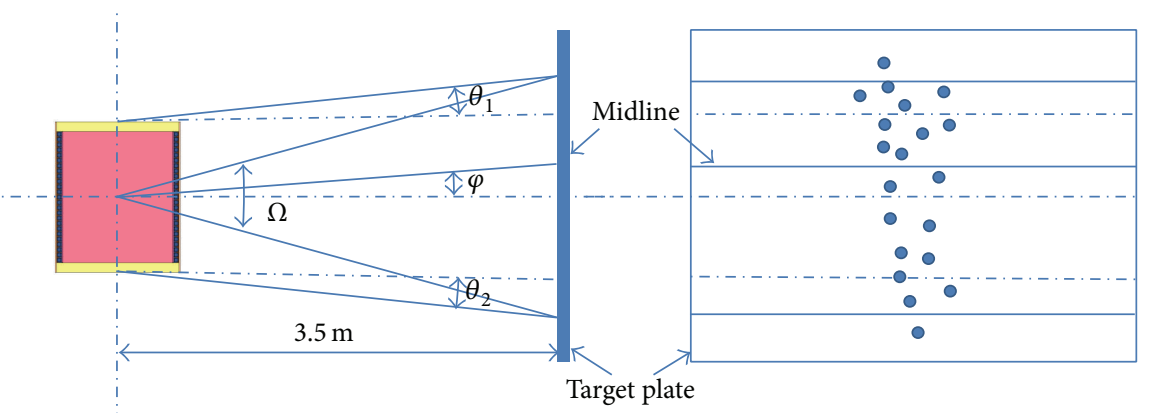

FIgURE 11: Ejection angle $(\Omega)$, direction angle $(\varphi)$, and deflecting angle $(\theta)$.

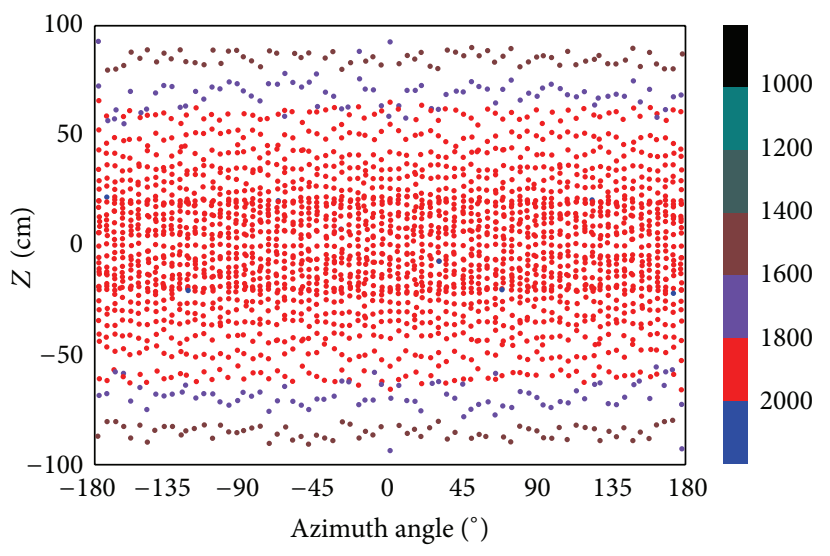

(a) Cylindrical structure

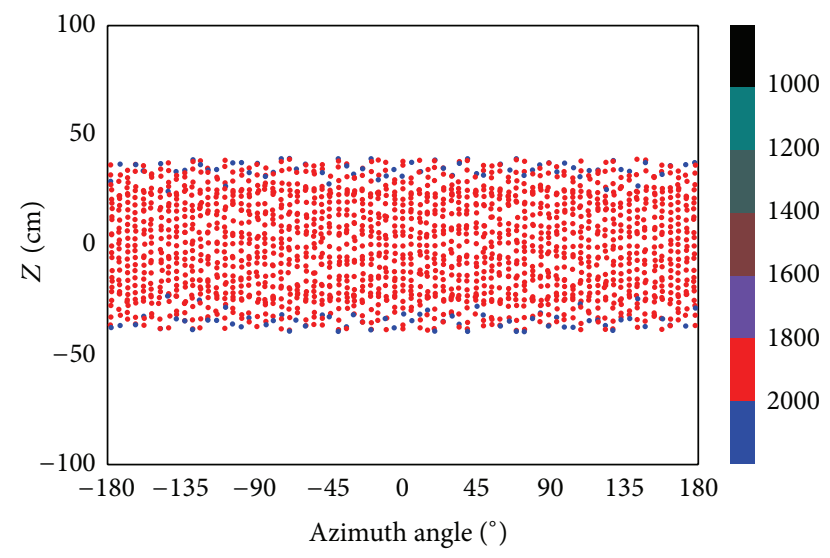

(b) Modified structure with platform

FIGURE 12: Fragment distributions on the target plant (distance 3.5 meters).

4.1. Model and Material. The numerical model of the parallel fragmentation structure is developed with the nonlinear, explicit finite element code LS-DYNA. This software is particularly suitable for nonlinear dynamic problems, such as impact or explosion. It allows for the application of different algorithms such as Euler, Lagrange, arbitrary Lagrange-Euler
(ALE), and SPH to solve the fluid-structure problems [2628].

Eight-node brick elements with ALE were adopted for the structure. Since the ALE approach uses meshes that are embedded in material and deform with the material, it combines the best features of both Lagrange and Euler 


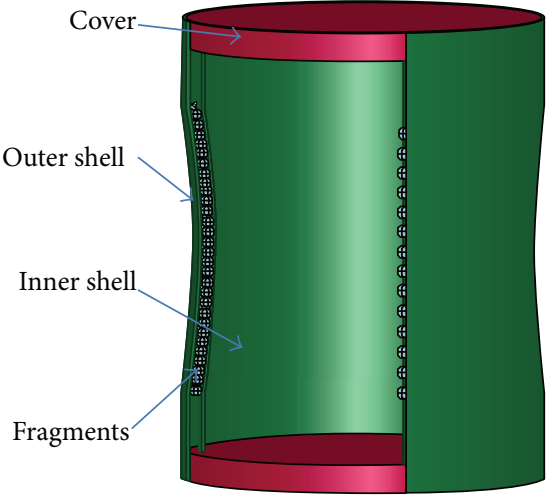

(a) Lag

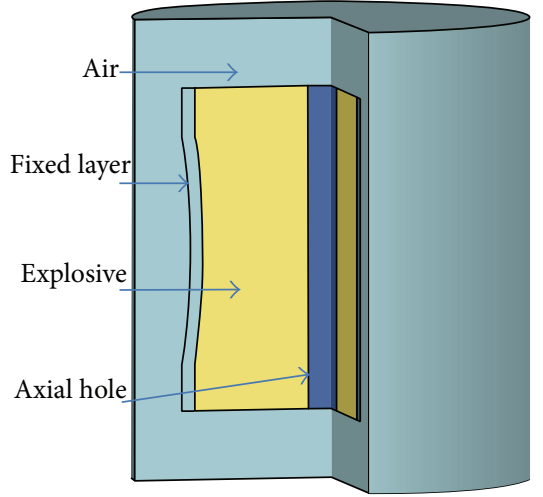

(b) Euler

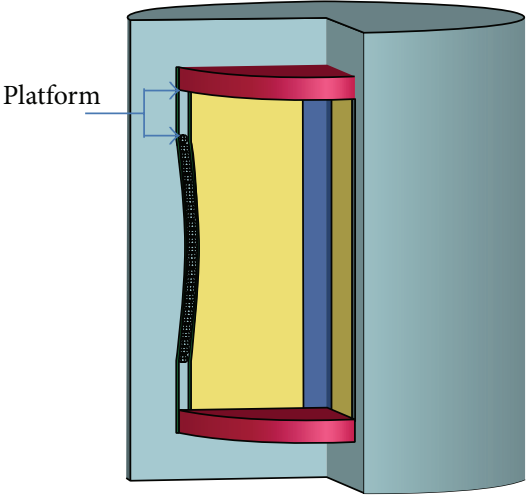

(c) Whole

FIGURE 13: Numerical model.

methods and allows the mesh within any material region to be continuously adjusted in arbitrary and predefined ways as the calculations proceed. Therefore, the ALE approach is suitable to analyze the process of explosion and fragments spraying away from the shell.

4.1.1. Numerical Model. As shown in Figure 13, the numerical model of a parallel fragmentation structure is separated into Lagrange model and Euler model, including cover, outer shell, inner shell, fragments, air, fixed layer, explosive, and axial hole. The fragments are arranged in the fixed layer between the inner shell and the outer shell, filled with epoxy resin. The platform is used to minimize the end effects. If the explosive is detonated from the geometrical center of the structure in the experiments, the axial hole should exist in the middle of the structure for the exploder. In order to be more consistent for experiments, an axial hole full of sponge is considered in the numerical model and the diameter of the hole is $32 \mathrm{~mm}$.

According to the various functions of the structure, the magnitude of the structure differs, as do the size of fragments and the thickness of the shell. The parallel fragmentation structure designed in this paper is suitable for airborne missiles. In the simulations, the height and the diameter of the structure range from $150 \mathrm{~mm}$ to $300 \mathrm{~mm}$. All the fragments are spheres, whose diameters are $6 \mathrm{~mm}$. The thickness of the shells is $1.5 \mathrm{~mm}$.

4.1.2. Modeling Material. A high explosive material model $\left({ }^{*}\right.$ MAT_HIGH_EXPLOSIVE_BURN) incorporating the JWL equation of state (EOS_JWL) was used to describe the material property of the RDX charge. The EOS_JWL equation defines the pressure as a function of relative volume and internal energy per initial volume; that is,

$$
p=A\left(1-\frac{\omega}{R_{1} V}\right) e^{-R_{1} V}+B\left(1-\frac{\omega}{R_{2} V}\right) e^{-R_{2} V}+\frac{\omega E}{V},
$$

where $p$ is the blast pressure, $E$ is the internal energy per initial volume, $V$ is the initial relative volume, and $\omega, A, B$, $R_{1}$, and $R_{2}$ are material constants, respectively.
The key material types and material properties of cover, shell, fragment, and RDX charge, as well as the parameters of equations of state, are listed in Table 2.

4.2. Factors Influencing Fragment Spatial Distribution. For different kinds of structures, the factors influencing fragment spatial distribution are different and include initiating method, material type, thickness of shells, size of fragment, type of explosive, height of platform, and magnitude of the whole structure. Because the majority of the influencing factors are fixed in this paper, some factors are taken into account for the design of the parallel fragmentation structure.

4.2.1. Type of Explosive. The fragments spraying away from the structure are closely connected to the problems of the explosives loading and responding. The type of explosive and the design of the structure are considerable factors influencing fragment spatial distribution. Seven types of explosives are considered, and the density and the detonation velocity of explosives are shown in Table 1 . Three representative kinds of structures are simulated, including the cylindrical structure, the parallel structure with no platform, and the parallel structure with $30 \mathrm{~mm}$ height platform. Based on the cylindrical structure with $200 \mathrm{~mm}$ height and $200 \mathrm{~mm}$ diameter, the other two kinds of structures are modeled.

Figure 14 shows the relationship between the deflecting angle and the density or the detonation velocity of explosives. In Figure 14(a), the deflecting angle of the parallel structure with platform is $0^{\circ}$, approximately. Because of the end effects, the deflecting angle of the structure with no platform increases by $3^{\circ} \sim 5^{\circ}$, and the angle of the cylindrical structure increases to $9^{\circ}$. Obviously, the design of the platform minimizes the end effects efficiently. Besides, the performance of the explosive does indeed make a difference to the end effects. The higher the energy of explosive is, the stronger the end effects are. As shown in Figure 14, the deflecting angles of the cylindrical structure and the parallel structure with no platform increase in a certain range, increasing the density and the detonation velocity of explosives. However, the type of explosive does not have too much effect on the deflecting angle of the parallel structure with platform. In this paper, we 
TABLE 2: Input data in the numerical simulation.

\begin{tabular}{|c|c|c|c|c|c|c|c|c|}
\hline \multirow{4}{*}{$\begin{array}{l}\text { Material } \\
\begin{array}{l}\text { LS-12 } \\
\text { aluminum alloy }\end{array}\end{array}$} & \multirow{4}{*}{$\begin{array}{l}\text { Part } \\
\text { Cover }\end{array}$} & \multicolumn{7}{|c|}{$\begin{array}{l}\text { LS-DYNA material type, material property, and EOS input data } \\
\qquad \text { (unit }=\mathrm{cm}, \mathrm{g}, \mu \mathrm{s}, \mathrm{Mbar})\end{array}$} \\
\hline & & \multicolumn{7}{|c|}{ " MAT_ELASTIC_PLASTIC_HYDRO_SPALL } \\
\hline & & $\mathrm{RO}$ & $G$ & SIGY & $\mathrm{EH}$ & PC & FS & \\
\hline & & 2.73 & 0.265 & $2.95 E-3$ & $8.384 E-3$ & -9.0 & 0.4 & \\
\hline \multirow{3}{*}{1020 steel } & \multirow{3}{*}{$\begin{array}{l}\text { Inner shell } \\
\text { Outer shell }\end{array}$} & \multicolumn{7}{|c|}{${ }^{*}$ MAT_ELASTIC_PLASTIC_HYDRO_SPALL } \\
\hline & & RO & $G$ & SIGY & $\mathrm{EH}$ & $\mathrm{PC}$ & \multicolumn{2}{|l|}{ FS } \\
\hline & & 7.85 & 0.618 & $7.24 E-3$ & 0.28 & -7.03 & 0.36 & \\
\hline \multirow{3}{*}{ Steel } & \multirow{3}{*}{ Fragment } & \multicolumn{7}{|c|}{${ }^{*}$ MAT_PLASTIC_KINEMATIC } \\
\hline & & $\mathrm{RO}$ & $E$ & $\mathrm{PR}$ & SIGY & ETAN & \multirow{2}{*}{$\begin{array}{c}\text { BETA } \\
0.36\end{array}$} & \\
\hline & & 7.89 & 2.069 & 0.3 & $1.724 E-2$ & 0.28 & & \\
\hline \multirow{6}{*}{ RDX } & \multirow{6}{*}{ Explosive } & \multicolumn{7}{|c|}{${ }^{*}$ MAT_HIGH_EXPLOSIVE_BURN } \\
\hline & & $\mathrm{PO}$ & $D$ & PCJ & & & & \\
\hline & & 1.65 & 0.818 & 0.3 & & & & \\
\hline & & \multicolumn{7}{|c|}{${ }^{*}$ EOS_JWL } \\
\hline & & $A$ & $B$ & $R 1$ & $R 2$ & OMEG & $E 0$ & $V 0$ \\
\hline & & 8.71 & 0.139 & 4.6 & 1.15 & 0.3 & 0.1 & 1.0 \\
\hline
\end{tabular}
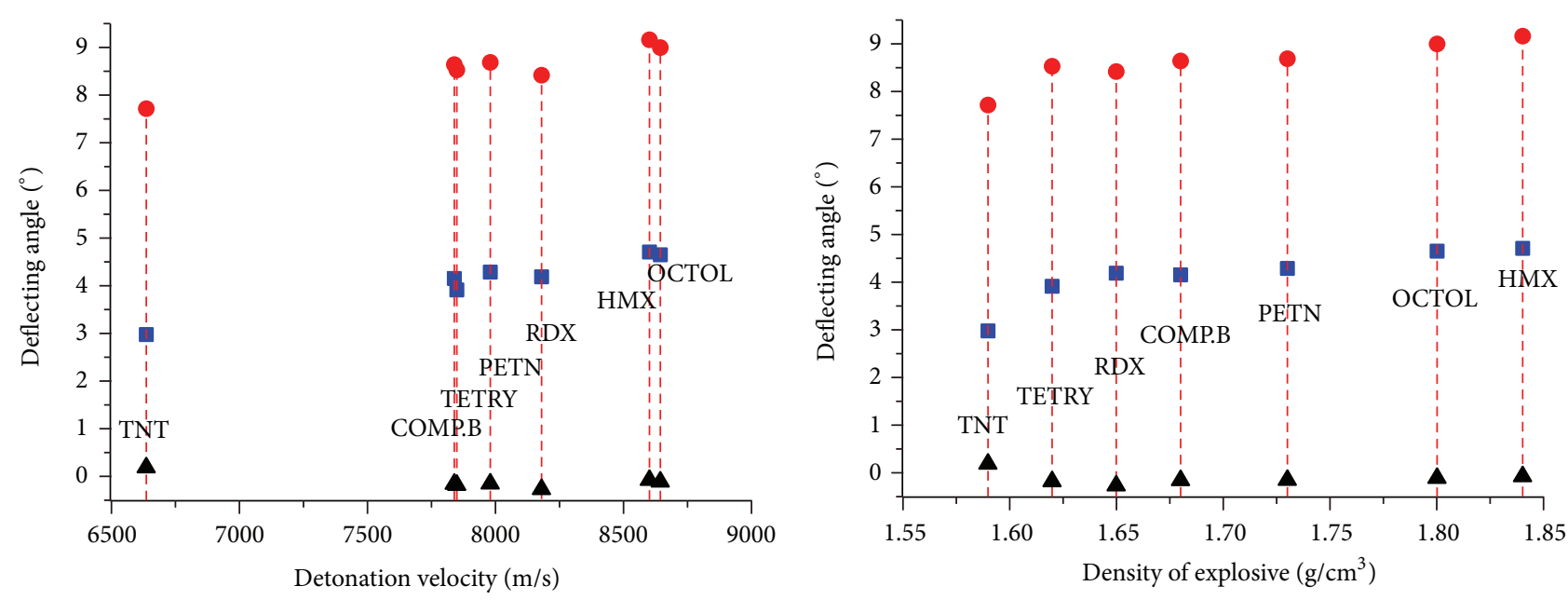

- Cylindrical warhead

- Parallel warhead with no platform

- Parallel warhead with platform

- Cylindrical warhead

- Parallel warhead with no platform

A Parallel warhead with platform

(a) Detonation velocity

(b) Density of explosive

FIGURE 14: Deflecting angle of structures with various explosives.

do not focus on the type of explosive, and the explosive of the following structures is RDX.

4.2.2. Height of Platform. The platform is an efficient way to minimize the end effects, but the size of the structure is always limited in a missile. It is necessary to determine the most suitable platform height for the parallel structure designed.

Figure 15 gives the relationship between the height $(h)$ of platform and the deflecting angle $(\theta)$ of five structures of varying sizes. It is clear that the influence caused by the platform on the fragment spatial distribution depends on the height of the platform. The end effects become weak with increasing the platform height and can be ignored when the platform height is nearly beyond a value, where the deflecting angle tends to be stable. Referring to the numerical calculation shown in Figure 15, the height of platform is suitable to $30 \mathrm{~mm}$. The $30 \mathrm{~mm}$ height platform has minimized the end effects considerably.

4.3. Structure Optimization. The height and diameter of the structures of airborne missiles range from $150 \mathrm{~mm}$ to $300 \mathrm{~mm}$. As depicted in Table 3, eighteen parallel fragmentation structures designed by the theoretical method, proposed 


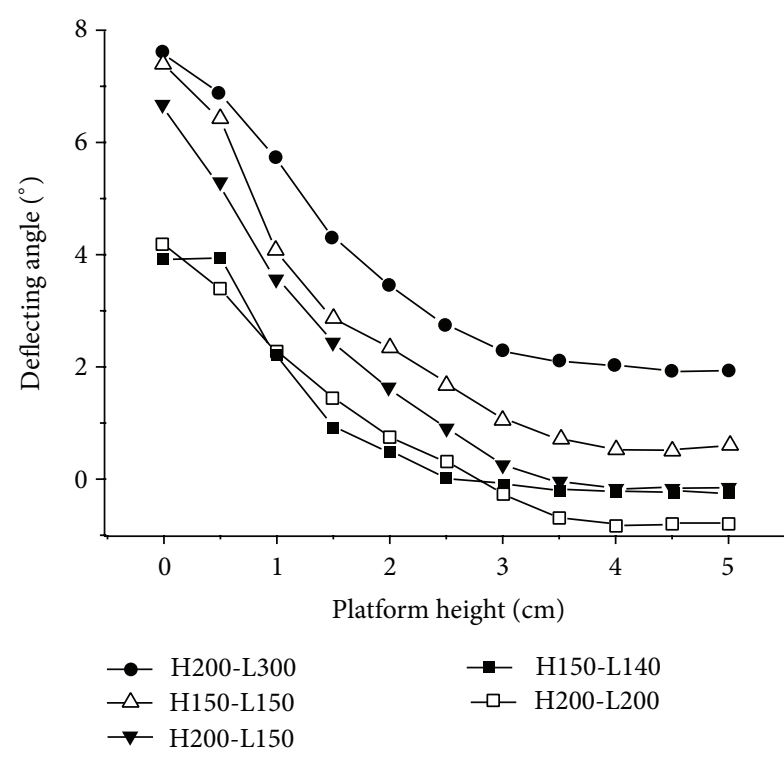

FIGURE 15: Relationship between the platform height $(h)$ and the deflecting angle $(\theta)$.

TABLE 3: Size of structures and optimum curvature radius.

\begin{tabular}{lccc}
\hline Number & $\begin{array}{c}\text { Height } \\
(\mathrm{mm})\end{array}$ & $\begin{array}{c}\text { Diameter } \\
(\mathrm{mm})\end{array}$ & $\begin{array}{c}\text { Radius } \\
(\mathrm{cm})\end{array}$ \\
\hline 1 & 300 & 300 & 88.13 \\
2 & 300 & 250 & 97.57 \\
3 & 300 & 200 & 112.52 \\
4 & 300 & 150 & 153.61 \\
5 & 250 & 300 & 76.04 \\
6 & 250 & 250 & 82.76 \\
7 & 250 & 200 & 95.12 \\
8 & 250 & 150 & 128.48 \\
9 & 200 & 300 & 63.00 \\
10 & 200 & 250 & 66.17 \\
11 & 200 & 230 & 68.96 \\
12 & 200 & 200 & 81.15 \\
13 & 200 & 150 & 108.42 \\
14 & 150 & 300 & 48.52 \\
15 & 150 & 250 & 52.08 \\
16 & 150 & 200 & 58.58 \\
17 & 150 & 150 & 74.53 \\
18 & 150 & 140 & 81.71 \\
\hline
\end{tabular}

in this paper, are modeled and the processes that fragments spray away from the shell are simulated.

The design of the shell shape is the key technology of the parallel fragmentation structure. The method of design depicted in Section 2.3 is imperfect, since it ignores the end effects and the structure of the axial hole, so optimizing the curvature radius of the arc equalizing the generatrix of shell is necessary.

The optimum curvature radius differs from the theoretical radius in a range. For each of the eighteen structures,

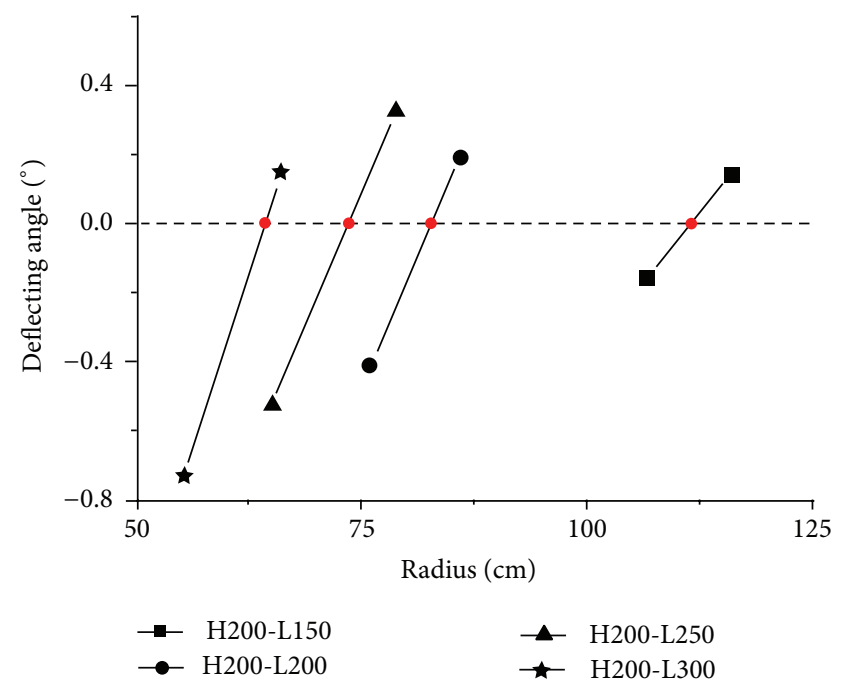

FIGURE 16: Optimum curvature radius.

TABle 4: Parameters of fitted relationship.

\begin{tabular}{lccccc}
\hline$z$ & $a$ & $b$ & $c$ & $d$ & $f$ \\
\hline 72.77 & 1.01 & -0.98 & $-6.37 E-4$ & $2.3 E-3$ & $-1.63 E-3$ \\
\hline
\end{tabular}

we continually rebuild the models which are of different curvature radius around the theoretical radius and simulate the process of spraying fragments. The optimum curvature radius is explored. When the curvature radius of the arc equalizing the generatrix of shell is the optimum curvature radius, the fragment deflecting angle is $0^{\circ}$. The accurate value of the optimum curvature radius is difficult to find, but we can make an approximation. The relationship between the radius and the deflecting angle is depicted in the coordinates shown in Figure 16, with radius as $x$-axis and deflecting angle as $y$ axis. A line passes through two points closest to the horizontal line $(Y=0)$ and intersects the line with a third point. The $X$ coordinate of the intersecting point is the optimum curvature radius. The optimum curvature radii of the eighteen parallel fragmentation structures are depicted in Table 3.

For a parallel fragmentation structure of any size, before the optimized curvature radius is obtained, it is complicated for us to complete a series of modeling and calculation processes. To avoid the complicated process of modeling and calculation, the relationships among the height $(H)$ and diameter $(L)$ of the parallel fragmentation structure and the optimized curvature radius $(R)$ are fitted into an equation as follows:

$$
R=z+a H+b L+c H^{2}+d L^{2}+f H L
$$

where $z, a, b, c, d$, and $f$ are constant, listed in Table 4 . The relationship is fitted by eighteen points depicted in Table 3 and the fitted curved surface is shown in Figure 17. Each point related to the optimized curvature radius can match the curved surface satisfactorily, so (11) can be a reliable reference for the design of the parallel fragmentation structure. 


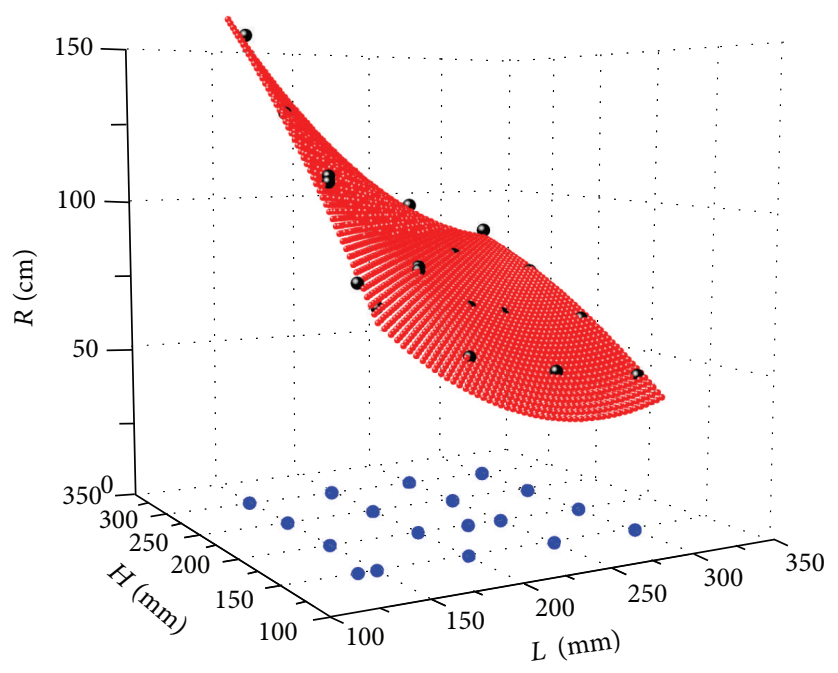

FIgURE 17: Fitted curved surface.

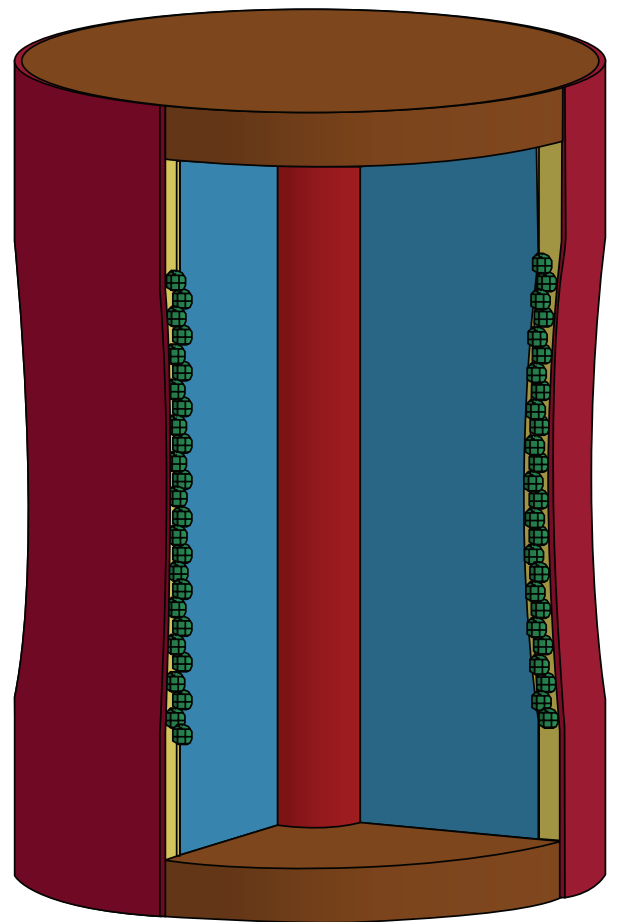

FIGURE 18: Model of a parallel structure.

4.4. Numerical Verification. In order to verify the veracity and reliability of (11), we design a parallel structure using (11) and simulate the process that fragments spray away from the shell. Based on the numerical information, we can get the fragmentation distributions in the space.

Taking a structure which is in any size into consideration, the height of the structure is $130 \mathrm{~mm}$; the diameter is $157.4 \mathrm{~mm}$. The parameter $H$ and the parameter $L$ in (11) can be expressed as

$$
H=130, \quad L=157.4 .
$$

Taking the above values into (11), we can get that the optimized curvature radius of the structure is $62.68 \mathrm{~cm}$. According to the design above, the parallel structure has $30 \mathrm{~mm}$ high platforms on each end, the diameter of fragments is $6 \mathrm{~mm}$, and the thickness of the shells is $1.5 \mathrm{~mm}$. The model of the parallel structure is shown in Figure 18. The structural components and the modeling materials are equal to the model in Section 4.1.

According to the numerical simulation, we can get the process that fragments spray in the space. The side views of fragmentation distributions are shown in Figure 19. It is 


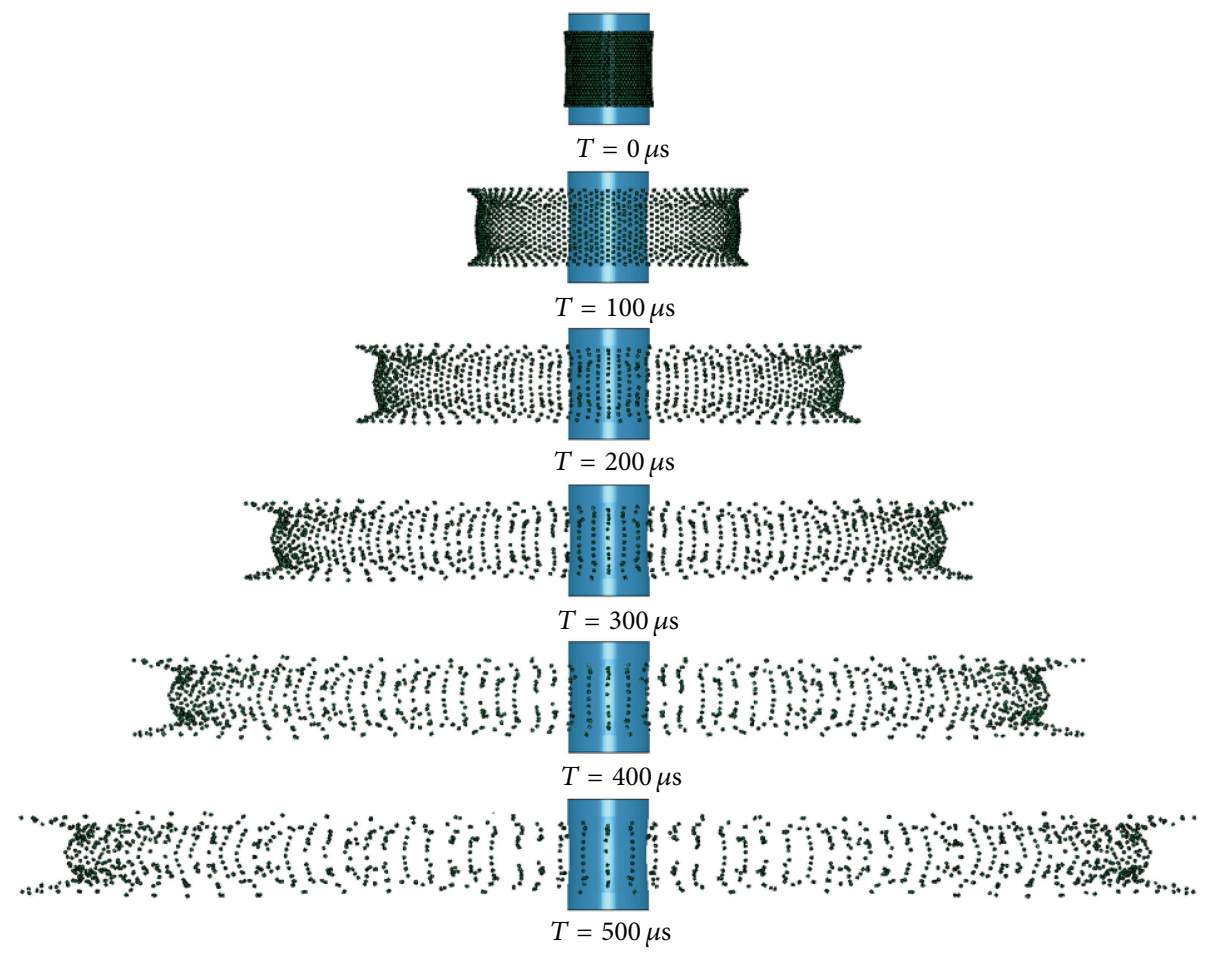

FIGURE 19: Side view of fragments spraying in the space.

clear that all the fragments keep spraying parallelly. Along axial direction of the parallel structure, the velocities of fragments are zero, and the distributions of fragments range from $-6.04 \mathrm{~cm}$ to $6.15 \mathrm{~cm}$. The deflecting angle of fragments is $-0.04^{\circ}$, which is highly approximate to $0^{\circ}$. It is verified that (11) can be a reliable method for the rapid design of parallel fragmentation structure.

The velocity is an important parameter to evaluate the performance of fragments, as well as the fragmentation distribution. In the model of the parallel fragmentation structure, 26 layer fragments are arranged crisscross in the interlayer between the inner shell and the outer shell. There are 74 fragments in each layer. The number of all the fragments is 1924. At 3.5-meter distance from the initial position of the structure, the average velocity of all the fragments is $1732.19 \mathrm{~m} / \mathrm{s}$, and the average velocities of fragments in each layer are different, as shown in Figure 20.

Showing the more features of the parallel fragmentation structure proposed in this paper, the propagation process of detonation wave in the explosive is displayed in Figure 21. In the simulation, the explosive of the model is initiated from the center of the structure. The detonation wave is a spherical wave and reflects on the boundary of explosive at $14 \mu \mathrm{s}$.

\section{Conclusion}

The experiments conducted in this paper in respect of the conventional cylindrical structure adequately indicate that the end effects and detonated method play important roles in the fragment spatial distribution. When the fragment distribution of conventional cylindrical structures, along the

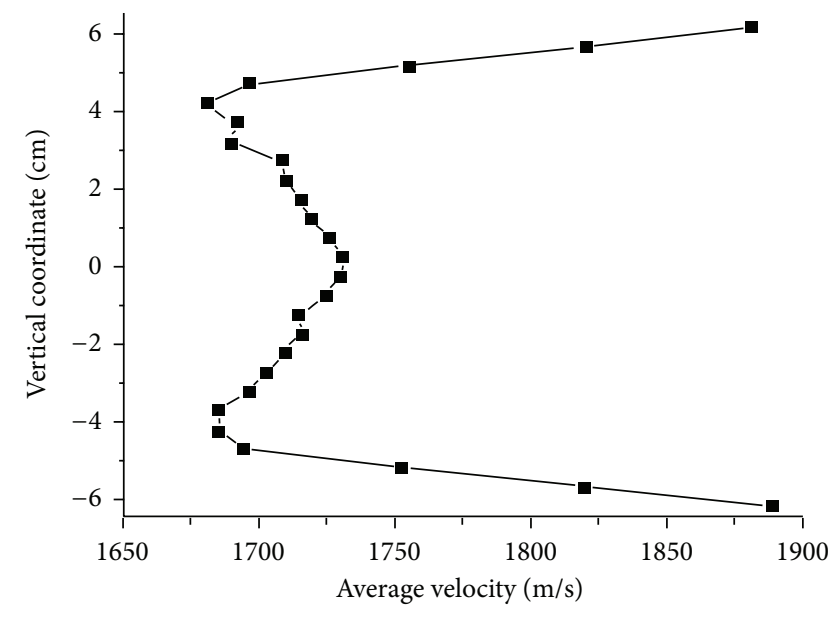

FIGURE 20: Average velocity of fragments in each layer.

axial direction, is in a wide range, the density of fragments on the target is low. For the focusing fragmentation warhead, the ability to focus fragments can only be achieved in a constant distance. Considering the disadvantages of the conventional structure and the specific structure of focusing fragmentation warhead, the parallel fragmentation structure designed in this paper overcomes these disadvantages. The significant characteristic of the parallel fragmentation structure is that fragments spray in parallel, which can not only improve the utilization ratio of fragments, but also achieve cutting damage to the target. 

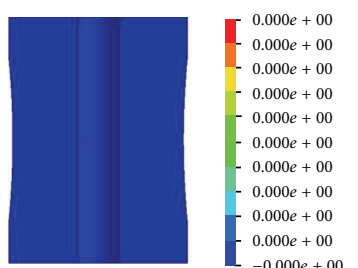

$T=0 \mu \mathrm{s}$

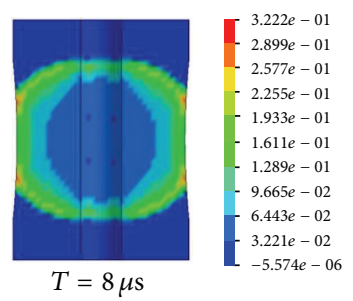

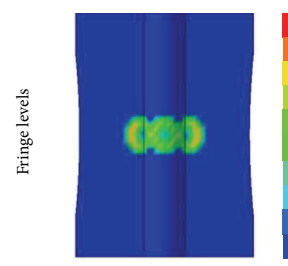

$T=2 \mu \mathrm{s}$

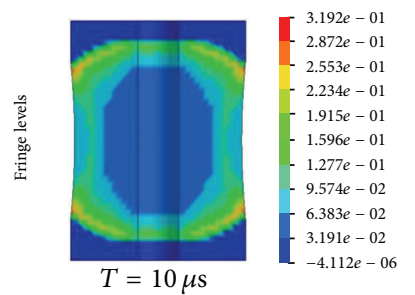

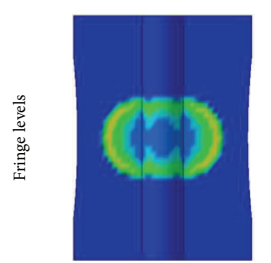

$T=4 \mu \mathrm{s}$

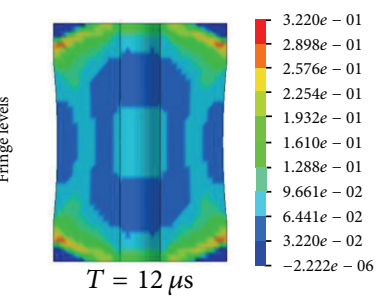

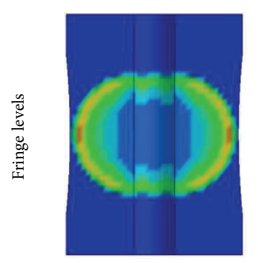

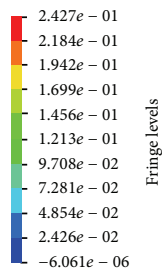

$T=6 \mu \mathrm{s}$

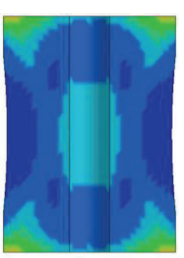

$T=14 \mu \mathrm{s}$

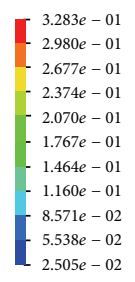

FIGURE 21: Propagation process of detonation wave in the explosive.

The process that fragments spray away from the shell is studied, and a new method to design the shell shape is used. The theoretical shell shape of the parallel fragmentation structure is calculated through the finite element method. To facilitate the establishment of the numerical model and the machining for relative experiments, the mathematical description for the generatrix of the shell is simplified. There are many factors influencing the distribution of fragments. A number of factors are fixed in this paper and some of the other factors are taken into account.

Regarding the structures of airborne missiles, their height and diameter range from $150 \mathrm{~mm}$ to $300 \mathrm{~mm}$. The eighteen parallel fragmentation structures designed through the theoretical method, proposed in this paper, are modeled and the processes that fragments spray away from the shell are simulated. Based on the theoretical design and plentiful simulation data, the relationships between the size of parallel fragmentation structure and the optimized curvature radius of the shell can be represented by an equation. The equation is validated by numerical means and can be a reliable reference to the design of the parallel fragmentation structure.

\section{Conflict of Interests}

The authors declare that there is no conflict of interests regarding the publication of this paper.

\section{Acknowledgment}

This work has been sponsored by the National Natural Science Foundation of China under Grants nos. 11132012 and 11202237.

\section{References}

[1] Y. Pei, B.-F. Song, and Q. Han, "Method for assessing the vulnerability of aircraft to spray fragments of missile," System Engineering Theory and Practice, vol. 27, no. 2, pp. 161-166, 2007.
[2] J. Li, W. Yang, Y. Zhang, Y. Pei, Y. Ren, and W. Wang, "Aircraft vulnerability modeling and computation methods based on product structure and CATIA," Chinese Journal of Aeronautics, vol. 26, no. 2, pp. 334-342, 2013.

[3] M. Held, "Fuze sensor requirements of the different amiable anti air warhead layouts," in Proceedings of the 23rd International Symposium on Ballistics, pp. 77-86, Tarragona, Spain, 2007.

[4] J. D. Hughes, “Tactical air warfare of the future," Journal of Aircraft, vol. 15, no. 3, pp. 134-136, 1978.

[5] M. Held, "Aimable fragmenting warhead," in Proceedings of the 13th International Symposium on Ballistics, pp. 539-548, Stockholm, Sweden, 1992.

[6] G. E. Fairlie, C. O. Marriott, N. J. Robertson, I. H. Livingstone, and N. K. Birnbaum, "Computer modeling of full size fragmenting amiable warheads using AUTODYN-3D," in Proceedings of the 17th International Symposium on Ballistics, pp. 389-396, Midrand, South Africa, 1998.

[7] L. Tong, Q. Lixin, and Z. Shouqi, "Study on fragment focusing mode of air-defense missile warhead," Propellants, Explosives, Pyrotechnics, vol. 23, no. 5, pp. 240-243, 1998.

[8] G.-Y. Huang, S.-S. Feng, F. Wang, and T. Zhou, "An optical design theory for focused fragmentation warhead," Defence Science Journal, vol. 62, no. 4, pp. 205-211, 2012.

[9] S.-S. Feng and G.-Y. Huang, "New design method for focusing fragments of warheads based on theory of optics," in Proceedings of the 25th International Symposium on Ballistics (ISB '10), pp. 926-935, Beijing, China, May 2010.

[10] X.-S. Kong, W.-G. Wu, J. Li, P. Chen, and F. Liu, "Experimental and numerical investigation on a multi-layer protective structure under the synergistic effect of blast and fragment loadings," International Journal of Impact Engineering, vol. 65, pp. 146-162, 2014.

[11] J.-Q. Liu, W.-B. Gu, M. Lu, H.-M. Xu, and S.-Z. Wu, "Formation of explosively formed penetrator with fins and its flight characteristics," Defence Technology, vol. 10, no. 2, pp. 119-123, 2014.

[12] W. W. Predebon, W. G. Smothers, and C. E. Anderson, "Missile warhead modeling: computations and experiments," Tech. Rep. 2796, Menmorandum, 1977.

[13] F. Lu, B. Jiang, X. Li et al., The Projection and Damage of Weapon Warhead, Science Press, Beijing, China, 2013, (Chinese). 
[14] P. Weng, G. Ren, and Q. Yu, Range Experiment of Ammunition, Weapon Industry Press, Beijing, China, 1996, (Chinese).

[15] R. M. Lloyd, Physics of Direct Hit and Near Miss Warhead Technologies, AIAA, Reston, Va, USA, 2001.

[16] R. M. Lloyd, Conventional Warhead Systems Physics and Engineering Design, AIAA, Reston, Va, USA, 1998.

[17] S. Sui and S. Wang, Terminal Effects, National Defence Industry Press, Beijing, China, 2007, (Chinese).

[18] R. W. Gurney, "The initial velocities of fragments from bombs, shells and grenades," Report 405, Ballistics Research Laboratories, Aberdeen, Md, USA, 1943.

[19] D. K. Crabtree and S. S. Waggener, "Gurney-type formulas for estimating initial fragment velocities for various warhead geometries," Internal Report NSWC TR NO. 86-241, Naval Surface Weapons Center, Dahlgren, Va, USA, 1987.

[20] M. H. Keshavarz and A. Semnani, "The simplest method for calculating energy output and Gurney velocity of explosives," Journal of Hazardous Materials, vol. 131, no. 1-3, pp. 1-5, 2006.

[21] A. Zlatkis, N. Korin, and E. Gofman, "Edge effects on fragments dispersion," in Proceedings of the 23rd International Symposium on Ballistics, pp. 177-184, Tarragona, Spain, 2007.

[22] P. C. Chou, J. Carleone, W. J. Flis, R. D. Ciccarelli, and E. Hirsch, "Improved formulas for velocity, acceleration and projection angle of explosively driven liners," Propellants, Explosives, Pyrotechnics, vol. 8, no. 6, pp. 175-183, 1983.

[23] P. J. Koenig, "A correction for ejection angles of fragments from cylindrical warheads," Propellants, Explosives, Pyrotechnics, vol. 12, no. 5, pp. 154-157, 1987.

[24] K. D. Dhote, K. P. S. Murthy, K. M. Rajan, and M. M. Sucheendran, "Quantification of projection angle in fragment generator warhead," Defence Technology, vol. 10, no. 2, pp. 177-183, 2014.

[25] G. Randers-Pehrson, "An improved equation for calculating fragment projection angle," in Proceedings of the 2nd International Symposium on Ballistics, pp. 223-226, Datona Beach, Fla, USA, 1976.

[26] L. Jing, Z. Wang, and L. Zhao, "Dynamic response of cylindrical sandwich shells with metallic foam cores under blast loadingnumerical simulations," Composite Structures, vol. 99, pp. 213223, 2013.

[27] X. Kong, W. Wu, J. Li, F. Liu, P. Chen, and Y. Li, "A numerical investigation on explosive fragmentation of metal casing using Smoothed Particle Hydrodynamic method," Materials and Design, vol. 51, pp. 729-741, 2013.

[28] J. Leppänen, "Experiments and numerical analyses of blast and fragment impacts on concrete," International Journal of Impact Engineering, vol. 31, no. 7, pp. 843-860, 2005. 


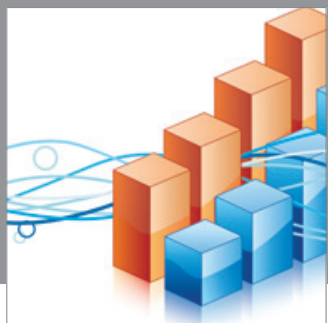

Advances in

Operations Research

mansans

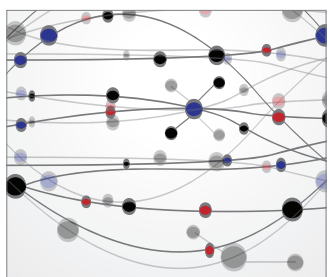

The Scientific World Journal
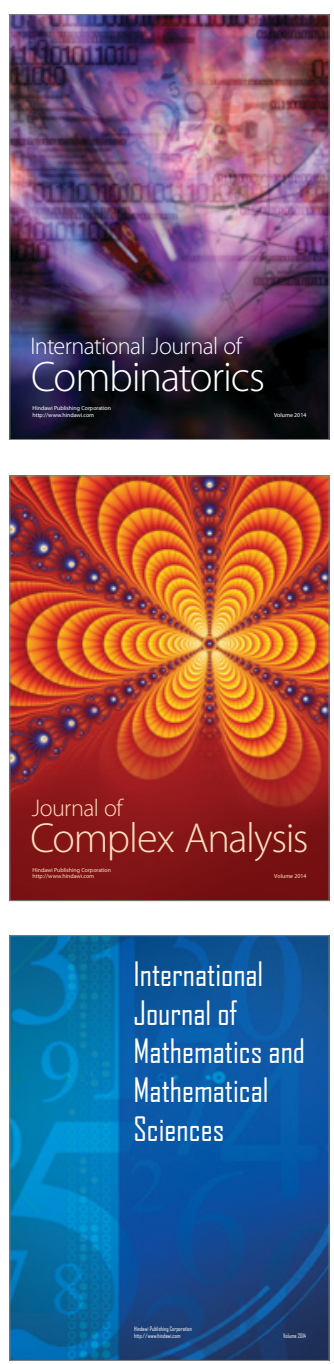
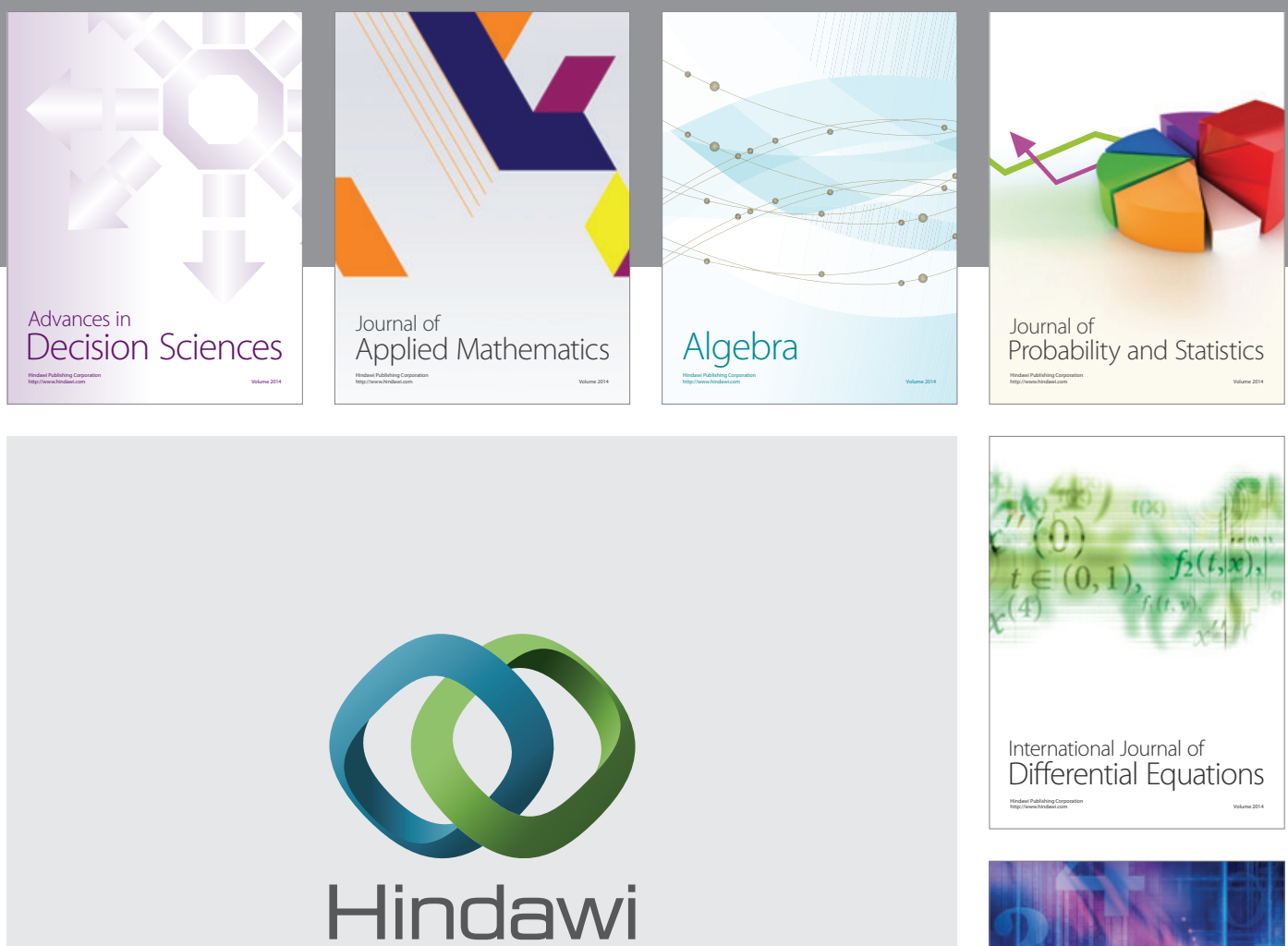

Submit your manuscripts at http://www.hindawi.com
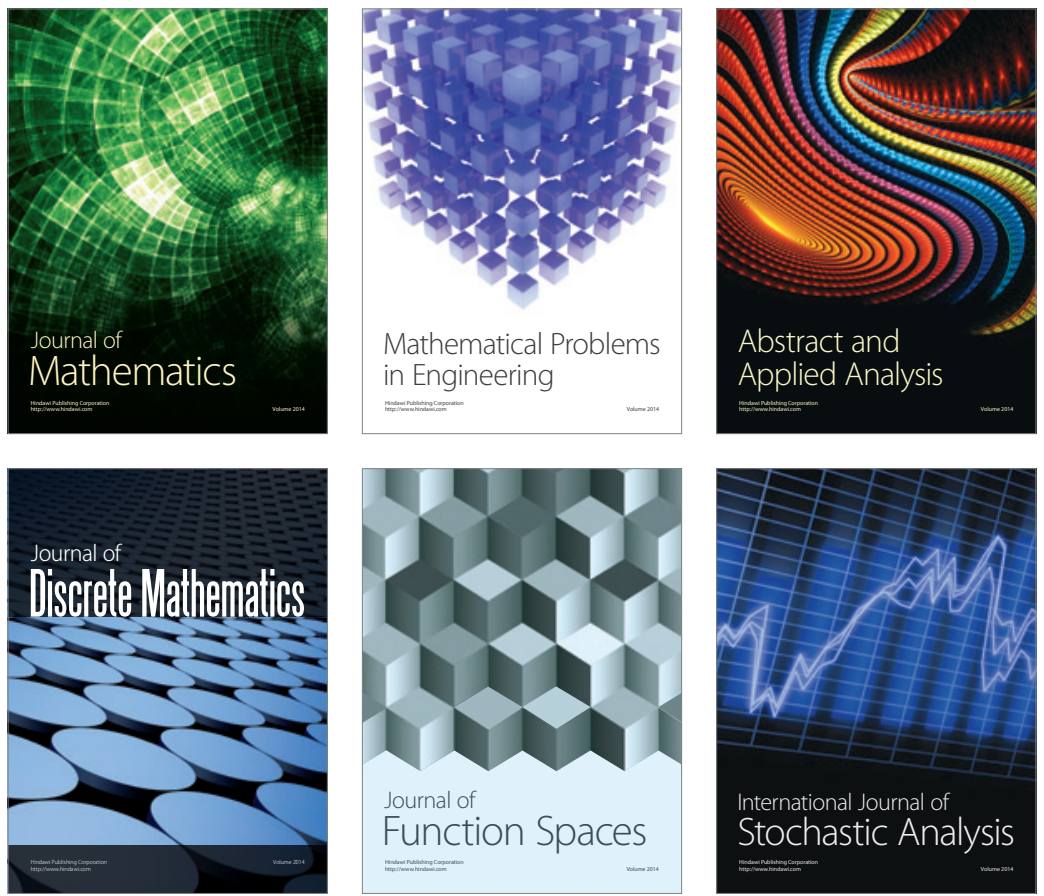

Journal of

Function Spaces

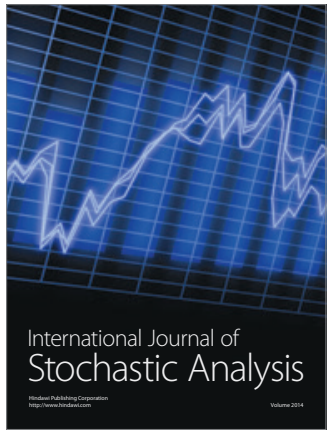

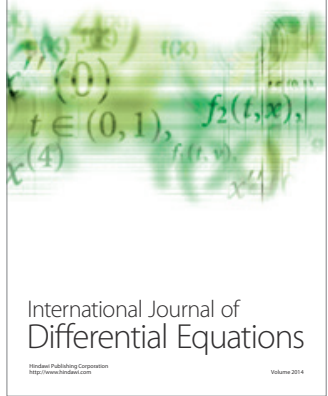
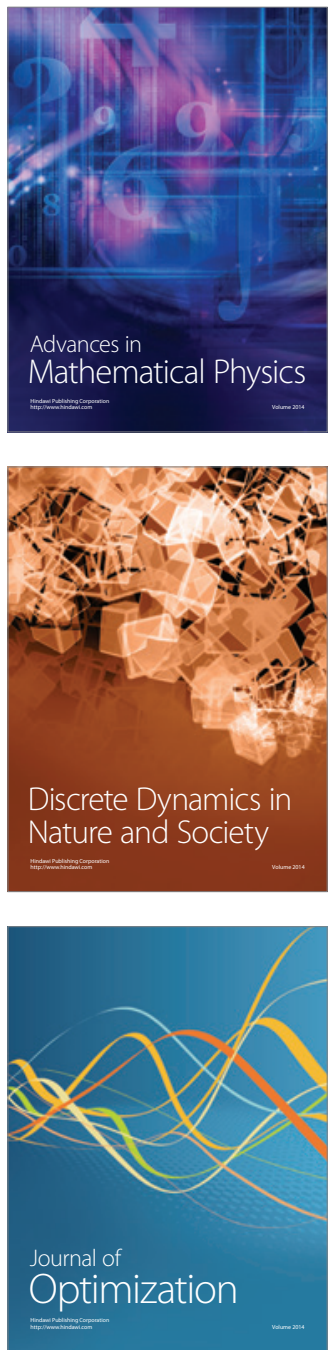